\title{
THE PREVALENCE OF HAMSTRING TIGHTNESS AMONG THE FOOTBALL PLAYERS
}

\author{
HARILAL \& DR.ANUSHA BHASKAR \\ ${ }^{I}$ Research Scholar, Sarvapalli Radhakrishan University, Bhopal and Sri Venkateshwara Research Centre, \\ Thanjavur, Tamil Nadu, India \\ ${ }_{2}^{2}$ Professor, Sarvapalli Radhakrishan University, Bhopal, Madhya Pradesh, India
}

\begin{abstract}
Muscle tightness is caused by a decrease in the ability of the muscle to deform, resulting in a decrease in the range of motion at the joint on which it acts. Tightness in hamstring muscles leads to hamstring injuries and hamstring injuries are the most common type of injury among athletes. These injuries are slow to recover, make high health expenditure and decrease the performance level of the athlete.

The objectives of this study are to find the prevalence of the hamstring tightness in football players and whether there is a relationship of hamstring tightness with body height; femoral length; duration of warm-up and cooldown period. This study is a preliminary study on the characteristics of the football players and the nature of the injuries they encounter.

KEYWORDS: Muscle Tightness, Injuries \& Football Players
\end{abstract}

Received: May 09, 2019; Accepted: Jun 29, 2020; Published: Jun 30, 2020; Paper Id.: IJMPERDJUN2020230

\section{INTRODUCTION}

Movement is dependent on the amount of range of motion (ROM) available in synovial joints. In general, ROM may be limited by 2 anatomical entities: joints and muscles. Joint restraint is due to joint geometry and congruency as well as the capsuloligamentous structures that surround the joint. Muscle provides both passive and active tension: passive muscle tension is dependent on structural properties of the muscle and surrounding fascia, while dynamic muscle contraction provides active tension.

Muscle tightness may be another important factor for reduced joint ROM. Muscle "tightness" results from an increase in tension from active or passive mechanisms. Passively, muscles can become shortened through postural adaptation or scarring; actively, muscles can become shorter due to spasm or contraction. Regardless of the cause, tightness limits range of motion and may create a muscle imbalance.

Therefore, it can be understood that muscle tightness is caused by a decrease in the ability of the muscle to deform, resulting in a decrease in the range of motion at the joint on which it acts [1]. Inability to achieve greater than $160^{\circ}$ of knee extension with hip at $90^{\circ}$ of flexion is considered as hamstring tightness [2]. Hamstring tightness leads to hamstring injuries and hamstring injuries are the most common type of injury among athletes. These injuries are slow to recover, make high health expenditure and decrease the performance level of the athlete.

\section{MATERIALS AND METHODS}

The present study determines the injuries to football players. The football players aged between 18 to 30 years. The 
data was collected with the help of questionnaires made by Cromwell and Gromley (2000) and researcher modified by the questionnaire and found out the test-retest reliability. Instructions were given to the footballers before filling these questionnaires by the researcher, football coach and football experts. The respondents were required to fill up the questionnaire and we collected data from 275 football players but after screening all football players included in this study. This study aims to determine the injuries among football players who are playing in the same sports. For the purposes of this study 50 inter-university football players various positions from various universities were represented Kerala or winners zone level/ inter-university football matches held in the year 2015 were randomly selected.

The Ethical Committee of the Faculty of Allied Health Sciences, University of Peradeniya, approved this study and all subjects gave their informed consent before participating in the study.

Each and every test was performed in separate stations by relevant examiners. Altogether there were four stations. The first station took the measurements of the body height, femoral length, and body weight. Femoral length was measured from upper part of the greater trochanter to lateral aspect of the base of the lateral epicondyle with an inch tape measure (Butterfly brand, China) with the subject lying supine. Body height was taken from vertex to toe tip to the nearest $0.1 \mathrm{~cm}$ using an inch tape measure (Butterfly brand, China). Body weight was measured by using a portable weight scale (Beurer, Germany).

Both left and right limb lengths were measured by using an inelastic tape measure (Butterfly brand, China) from the anterior superior iliac spine to the tip of the medial malleolus while subject lied supine to ascertain that there were no limb length discrepancies. Other than the above mentioned tests, the subjects were examined for scoliosis, congenital hip dislocation and for generalized ligament laxity. The range of motion was assessed for spinal flexion, extension, side flexion, and rotation.

Testing the hip joint movements and the hip joint examination were performed at the second station. The hip joint was assessed for range of motion of flexion, extension, abduction, adduction and medial and lateral rotation. Several tests were performed to examine the hip joint. Febers' test was used to identify the hip joint/sacroiliac joint dysfunction, and to identify the spasm of iliopsoas muscle. The Thomas test was performed to examine hip flexion contractures.

At the third station, knee joint examination was carried out. The knee joint was examined by using several tests, the Valgus test to examine the medial collateral ligament and the Varus test to examine the lateral collateral ligament. Lachmann test was performed to identify instability of the anterior cruciate ligament and the posterior drawers test was performed to identify posterior cruciate ligament. Applys' test was performed to examine the meniscus. For checking the patella femoral syndrome, the Patella grinding test was performed. Finally the hamstring tightness assessed by measuring the active knee extension angle of both knees with active knee extension test [3].

\section{RESULTS AND DISCUSSIONS}

Total 175 injuries out of 275 football players were found out over the one year of the period. Table 1 reveals that morphological characteristics of the footballers included in the study. This table also shows the duration of training.

Table 1: Morphological Characteristics Of Players

\begin{tabular}{|c|l|c|}
\hline S. No & \multicolumn{1}{|c|}{ Components } & Values \\
\hline 1. & Age (years) & $25.3 \pm 7.52$ \\
\hline 2. & Weight $(\mathrm{Kg})$ & $67.5 \pm 15.35$ \\
\hline 3. & Height $(\mathrm{cm})$ & $172.5 \pm 45.6$ \\
\hline
\end{tabular}




\begin{tabular}{|c|l|c|}
\hline 4. & Training (days/week) & $4.5 \pm 1.5$ \\
\hline 5. & Training duration (hours) & $2.5 \pm 0.5$ \\
\hline 6. & Warm up (minutes) & $10.0 \pm 2.5$ \\
\hline 7. & Competition in one year & $4.5 \pm 2.0$ \\
\hline
\end{tabular}

Table-1, shows that the morphological characteristics of the selected components of the football players. Mean Score (S.Ds.) age of football players was 25.30 (7.52) years, mean score (S.Ds.) weight was 67.5 (15.35) Kg., mean score (S.Ds.) height was $172.50(45.6) \mathrm{cm}$. the training related components of the football players are also accounted for in this table. Their training mean score (S.Ds.) was 4.50 (1.5) days, their training duration mean score (S.Ds.) was 2.5 (0.5) hours, their warm up mean score (S.Ds.) was 10.0 (2.5) minutes and competition mean score (S.Ds.) was 4.5 (2.0) in one year.

Table 2: Percentage of Location Wise Injuries Prevalence in Football Players

\begin{tabular}{|c|l|c|}
\hline No & \multicolumn{1}{|c|}{ Particulars } & Percentage \\
\hline 1. & Shoulder & 07.95 \\
\hline 2. & Ankle & 22.5 \\
\hline 3. & Knee & 20.5 \\
\hline 4. & Hamstring & 10.5 \\
\hline 5. & Groin & 8.2 \\
\hline 6. & Lower leg & 7.25 \\
\hline 7. & Hand & 5.05 \\
\hline 8. & Foot & 6.2 \\
\hline 9. & Upper arm & 4.2 \\
\hline 10 & Back & 2.5 \\
\hline 11. & Hip & 1.8 \\
\hline 12. & Elbow & 1.8 \\
\hline 13. & Chest & 2.0 \\
\hline
\end{tabular}

Table-2. shows that the percentage of injuries with respect to location among football players. $7.95 \%$ footballers sustained injuries in Shoulder, $22.5 \%$ in Ankle, 20.5\% in Knee, 20.5\% in hamstring, 8.2\% in Groin, 7.25\% in Lower Leg, $5.05 \%$ in hand, $6.2 \%$ in Foot, $4.2 \%$ in Upper Arm, $2.5 \%$ in Back, 1.8\% in Hip, 1.8\% in Elbow and 2.0\% in chest injuries sustained to the football players.

Keeping in view the fact that injuries have important health consequences during their participation in game, a large number of studies have been reported from different countries of the world. Data on the injuries from England, America Brazil, Ching, Russia and Europe are available in the literature, all these reports made the football expert realize the play affected due to injuries of football players.

Hamstring are most commonly site of injuries to footballers. The majority of injuries associated with football sustained the in the knees, groin, and ankles.(14). The most common causes of disorders of the knee are : (1) A torn medial meniscus cartilage ; (2) Subluxation of the patella ; (3) Sprains and tears of the all ligaments in the knee.

There are instances when athletes have more pain at rest and feel better and even eliminate pain on activity. It is also imperative that in the History taking the pain be described in standard terms, such as sharp, dull, radiating, aching, pressing, or squeezing. The functions at the foot in stance and motion are primarily stability, support, and secondarily propulsion at body weight under varied conditions. In order to function efficiently the structures must work in intricate balance, allowing effortless support, voluntary control, and effective propulsion, if this takes place, there is no energy wasted, no friction, extra motion, or protective inefficient activity. Over use implies that when the problems develop, the body is under conditioned. 
Two major categories of injuries are common in footballers, those caused by imbalance, and those caused by training, imbalance injuries of the foot may be described in terms of the reference planes at the body namely : (1) Saggital; (2) Flexion and extension; (3) Frontal (side to side) problems, inversion or reversion at the foot and ankle; (4) Transverse (rotational) problems, such as in toe, or out of toe, or secondary knee and hip torsional (twisting) problems. Imbalance of the foot will allow either direct training to the body or the body will compensate for the imbalance with additional stress in the form of the over-use, such as strain, muscle fatigue, cramps, tendinitis, or the stress fractures.

Table 3: Percentage of Injuries with Respect of Nature Among Football Players

\begin{tabular}{|c|l|c|}
\hline No & \multicolumn{1}{|c|}{ Nature of Injuries } & Percentage of Injuries \\
\hline 1. & Muscle & 54.25 \\
\hline 2. & Ligament & 22.2 \\
\hline 3. & Fracture & 8.5 \\
\hline 4. & Pain & 7.25 \\
\hline 5. & Others & 8.2 \\
\hline
\end{tabular}

In table $3 \mathrm{~s}$ the percentage of injuries with respect to nature among football players. Football players reported injuries in muscle $(54.25 \%)$, Ligament $(22.2 \%)$, Fracture $(8.5 \%)$, Pain $(7.25 \%)$, and others $(8.2 \%)$. Muscle and ligament are most occurrence injuries to football players.

Many risk factors including poor flexibility, strength imbalance, insufficient warm-up, and fatigue have been proposed as risk factors for hamstring strain injury. Basic science studies have established the connections between muscle strain and strain injury, muscle optimum length and muscle strain, and flexibility and muscle optimum length, which support poor flexibility and insufficient warm-up as risk factors for hamstring strain injury. However, the theoretical basis of hamstring strength imbalance and other proposed risk factors for hamstring strain injury is lacking. Sidhu and Wadhan [4] in their study concluded that among the Indian national Footballers, the forwards, half backs are quite similar to one another. They were shorter than the stoppers and goal keepers.

This study is a preliminary study on the characteristics of the football players and the nature of the injuries they encounter. This may further be extended to give an insight into the prevention of hamstring injury which is very common in these players.

\section{REFERENCES}

1. Akinpelu AO, Bakare U, Adegoke BOA (2005) Influence of age on hamstring tightness in apparently healthy Nigerians. Journal of the Nigeria society of physiotherapy 15: 35-41.

2. Waseem M, Nuhmani S, Ram CS (2009) Efficacy of Muscle Energy Technique on hamstring muscles flexibility in normal Indian collegiate males. Calicut Medical Journal 7: e4.

3. Gajdosik R, Lusin G (1983) Hamstring muscle tightness. Reliability of an activeknee-extension test. Phys Ther 63: 1085-1090.

4. Sidhu, L.S. and Wadhan, S.P.: A study of somatotype distribution of sportsmen specializing in different events. Sports Medicine, 4: 13 - 19 (1975).

5. GOSWAMI, ANURUPA, and DK SHARMA. "EMERGING PLAYERS IN AGING PROCESS: A REVIEW." International Journal of Applied and Natural Sciences (IJANS) 6.4 (2017):23-36

6. Puangplub, Chatchai, Sasichai Tanamai, And Watsatree Diteeyont. "Elements Of Mmorpgs Environment Affecting Skills Development Of Players." International Journal of Educational Science and Research (IJESR) 7.1 (2017):77-84 
7. Mohammed, Zerf, and Bengoua Ali. "Effect dimensional of delimiters on implementationof speed, balance and the agility in dribbling among soccer (under 15 year)." International Journal of Educational Science and Research (IJESR) 5.5 (2015): 6772.

8. Sudhakar, S., et al. "Efficacy of 6 week Plyometric training on agility performance in collegiate male basketball players." International Journal of Physiotherapy \& Occupational Therapy (TJPRC: IJPOT) 2.2 (2016): 1-8.

9. Arjunan, R. "Effect Of Circuit Training And Anaerobic Interval Training On Speed And Strength Among Men Handball Players." Best: International Journal Of Humanities, Arts, Medicine And Sciences (Best: Ijhams) 3.10 (2015):75-80

10. BISWAS, AVEEK, and NANDINI PRAMANIK. "GAME OF LIFE: LEARNINGS FROM SPORTS FOR PROFESSIONALS." International Journal of English and Literature (IJEL) Special Edition (2014):5-10.

11. Javed, Saeed, Abd Rahim Bin Mohd Shariff, And Shanmuga Nathan. "Influences Of Hockey Coaches, Team Cohesion And Motivational Intensity On The Performance Of Pakistani Field Hockey Players." Best: International Journal Of Humanities, Arts, Medicine And Sciences (Best: Ijhams) 3.3 (2015):53-62 

